\title{
Pedal laceration by the anemone Aiptasia pallida
}

\author{
William S. Clayton, Jr.* \\ Department of Biological Sciences, State University of New York at Buffalo, Buffalo, New York 14260, USA
}

\begin{abstract}
The significance of zooxanthellae and feeding regime on pedal laceration by the anemone Aiptasia pallida Verrill was studied in the laboratory by maintaining symbiotic and aposymbiotic individuals at varying feeding regimes. Pedal laceration was inversely related to feeding frequency and the presence of zooxanthellae increased pedal laceration rate of starved individuals. Lacerates produced by symbiotic individuals had a significantly greater dry weight than lacerates produced by aposymbionts. This difference can largely be explained by the presence of zooxanthellae in symbiotic lacerates which comprised 55 to $60 \%$ of lacerate dry weight. Development time and survival of lacerates to juvenile anemones was not significantly different for symbiotic and aposymbiotic lacerates and lacerate dry weight did not change significantly during development. These results suggest that zooxanthellae had little effect on lacerate development but enhanced pedal laceration rate during starvation.
\end{abstract}

\section{INTRODUCTION}

Many anthozoans are capable of some form of asexual reproduction (e.g. Stephenson, 1929; Chia, 1976). Possible advantages of asexual reproduction have recently received much consideration; they include: increased clone size and competitive ability (Francis, 1973a, 1976); reduced mortality from desiccation and wave action (Francis, 1973b, 1979); clone survival in unpredictable habitats (Minasian, 1982); increased clone prey capture ability (Smith and Lenhoff, 1976; Sebens, 1979, 1982a); and differential growth of locally successful genotypes (Hoffmann, 1976; Shick and Lamb, 1977; Shick et al., 1979). In addition, asexual reproduction (by an individual or colony) influences the amount of space occupied by the clone (Jackson, 1977a) as well as greatly affecting specific demographic parameters of the clone (Hughes and Jackson, 1980; Bak et al., 1981; Sebens, 1982b). Thus, at least in certain habitats, asexual reproduction has pronounced effects on both population and community structure.

In spite of the apparent ecological significance of asexual reproduction, the factors controlling when anemones reproduce asexually, and at what rate, are known for only a few species. In Haliplanella luciae fission rate is directly related to temperature (Mina-

\footnotetext{
- Present address: Department of Biology, Gettysburg College, Gettysburg, Pennsylvania 17325, USA
}

sian, 1979, 1982; Minasian and Mariscal, 1979), cyclic periods of immersion (Johnson and Shick, 1977) and feeding frequency (Minasian, 1976, 1979, 1982; Johnson and Shick, 1977; Minasian and Mariscal, 1979). Fission by Metridium senile is directly related to current velocity, which is also correlated with zooplankton availability (Shick and Hoffman, 1980). In contrast, feeding decreases the frequency of pedal laceration by an acontiarian anemone (Smith and Lenhoff, 1976; recently identified as Aiptasiogeton comatus by Minasian, 1982) and longitudinal fission by Anthopleura elegantisima (Sebens, 1980).

Many species capable of asexual reproduction also contain endosymbiotic algae, and the presence of these symbionts is known to affect certain aspects of host development and reproduction, including asexual reproduction. For instance, zooxanthellae enhance medusae strobilation by Mastigias papua (Sugiura, 1964), Cassiopea andromeda (Ludwig, 1969; Hofmann and Kremer, 1981) and C. xamachana (Trench, 1980). In addition, zoochlorellae increase sponge gemmule germination rate by Spongilla lacustris (Brondsted and Brondsted, 1953) and tentacle regeneration rate by Hydra viridis (Bossert and Slobodkin, 1983; Rahat and Reich, 1983). However, the only study of zooxanthellal effects on anthozoan asexual reproduction was that of Sebens (1980) who found no effect of darkness on the frequency of longitudinal fission by Anthopleura elegantissima. 
In this study I examined the effects of both zooxanthellae and feeding frequency on asexual reproduction (i.e. pedal laceration) by Aiptasia pallida. Results suggest that, under these conditions, zooxanthellae had little effect on lacerate development and that zooxanthellal effects on pedal laceration rate were dependent on feeding regime.

\section{MATERIALS AND METHODS}

Specimen maintenance. Specimens of Aiptasia pallida used in all experiments were originally derived from a single individual obtained from Carolina Biological Supply. Anemones were maintained in artificial sea water (Instant Ocean) at $26^{\circ} \mathrm{C} \pm 1 \mathrm{C}^{\circ}$ on a $14 \mathrm{~h}$ light $/ 10 \mathrm{~h}$ dark photoperiod with a light intensity of $65 \mu \mathrm{E} \mathrm{m} \mathrm{m}^{-2} \mathrm{~s}^{-1}$. Aposymbionts were produced by culturing anemones in a theoretical concentration of $10^{-5} \mathrm{M}$ 3-(3,4 dichlorophenyl)-1,1 dimethyl urea (DCMU) for 4 to $5 \mathrm{w}$. The actual concentration used was probably less than $10^{-5} \mathrm{M}$ since DCMU is only partially soluble in seawater (Vandermeulen et al., 1972). Anemones treated in this manner lost all coloration and microscopic examination of homogenized individuals at $300 \mathrm{X}$ showed no zooxanthellae present in the tissues. Experimental anemones were taken from cultures fed to repletion once per week with freshly hatched ( 24 to $48 \mathrm{~h}$ ) Artemia sp. nauplii.

Lacerate biomass, development time and survival. Lacerate biomass was examined by isolating groups of 10 randomly chosen symbiotic or aposymbiotic individuals in $500 \mathrm{ml}$ seawater. Pedal lacerates were collected daily and rinsed for $10 \mathrm{~s}$ in distilled water. They were then dried on preweighed pieces of aluminum foil for $24 \mathrm{~h}$ at $55^{\circ} \mathrm{C}$ and weighed (Perkin-Elmer autobalance/microbalance, model number AD-2).

Significance of zooxanthellae on lacerate development time was examined by maintaining groups of 10 randomly chosen symbiotic or aposymbiotic anemones as described previously. Lacerates produced by these individuals were inspected daily at $40 \mathrm{X}$ to determine if they had attained a specific developmental stage. Lacerates at this stage possess a stomodeum, tentacles and incomplete mesenteries (Fig. 4 in Cary, 1911) and will henceforth be referred to here as juvenile anemones. Development time was arbitrarily defined as the number of days required for a newly generated lacerate to develop into a juvenile anemone. At the completion of development the dry weight of juvenile anemones was determined as described for pedal lacerates.

The presence of zooxanthellae in symbiotic lacerates may affect lacerate biomass and influence dry weight comparisons of symbiotic and aposymbiotic lacerates.
The percentage of lacerate dry weight attributable to zooxanthellae was estimated by homogenizing 4 groups of 10 newly generated lacerates or juvenile anemones in $1 \mathrm{ml}$ distilled water with a teflon pestle for $30 \mathrm{~s}$. The resulting suspension was centrifuged for 3 min at $1700 \times \mathrm{g}$ and the animal fraction withdrawn by pipetting (Clayton, 1984). The remaining zooxanthellal pellet was resuspended in $0.5 \mathrm{ml}$ distilled water and withdrawn. Anemone and zooxanthellae fractions were dried on preweighed filters and weighed as described for the lacerate dry weight measurements. Clayton (1984) showed that this separation procedure on mature anemones yields a $14 \%$ animal tissue contamination of the zooxanthellal pellet and a $4 \%$ zooxanthellal contamination of the animal fraction. This results in a net contamination of the zooxanthellal pellet with animal tissue. If similar contamination of the zooxanthellal pellet occurs during the processing of pedal lacerates this may underestimate the animal biomass of symbiotic lacerates.

Lacerate survival to the juvenile anemone stage was examined by maintaining ten individual symbiotic or aposymbiotic anemones in separate vials with $50 \mathrm{ml}$ artificial seawater. Lacerates produced by these individuals during $7 \mathrm{~d}$ starvation were inspected daily at $40 \mathrm{X}$ to determine if they had developed into juvenile anemones. Survival was defined as the percentage of lacerates produced by each individual that developed into juvenile anemones.

Lacerate production. Lacerate production by individual anemones was studied by isolating 10 groups of 2 randomly chosen symbiotic or aposymbiotic anemones in separate vials with $15 \mathrm{ml}$ artificial seawater. Anemones were either starved, fed to repletion once per week, or fed to repletion $3 \mathrm{X}$ per week (every other day) with freshly hatched ( 24 to $48 \mathrm{~h}$ ) Artemia sp. nauplii. Vials were inspected daily for developing lacerates and the number of lacerates per individual recorded over a $30 \mathrm{~d}$ period.

\section{RESULTS}

\section{Lacerate biomass, development time and survival}

Symbiotic and aposymbiotic lacerate dry weight, development time and percent survival are presented in Table 1. A 2-way analysis of variance (ANOVA, Model I) for unequal but proportional sample sizes (Sokal and Rohlf, 1969) was used to test for lacerate dry weight differences between symbionts and aposymbionts and between newly generated lacerates and juvenile anemones. There was no signification difference in dry weight between lacerates and juvenile anemones $(\mathrm{P}>0.10 ; \mathrm{df}=1,64 ; \mathrm{F}=1.83)$ and no inter- 
Table 1. Aiptasia pallida. Comparison of various parameters between symbiotic and aposymbiotic lacerates ( $\overline{\mathrm{X}} \pm$ S.E.)

\begin{tabular}{|c|c|c|c|}
\hline Parameter & Symbiotic & Aposymbiotic & п \\
\hline Lacerate dry weight (mg) & $0.106 \pm 0.014$ & $0.036 \pm 0.004$ & 20 \\
\hline Juvenile anemone dry weight (mg) & $0.132 \pm 0.018$ & $0.046 \pm 0.005$ & 14 \\
\hline Development time (d) & $7.07 \pm 0.40$ & $6.27 \pm 0.30$ & 15 \\
\hline Survival $(\%)$ & $91.4 \pm 3.56$ & $92.2 \pm 4.78$ & 10 \\
\hline$\%$ Zooxanthellae by weight (lacerates) & $60.34 \pm 2.75$ & - & 4 \\
\hline$\%$ Zooxanthellae by weight (juvenile anemones) & $56.65 \pm 2.88$ & - & 4 \\
\hline
\end{tabular}

action effect ( $\mathrm{p}>0.75$; $\mathrm{df}=1,64 ; \mathrm{F}=0.001)$. However, there was a significant difference in dry weight between symbiotic and aposymbiotic lacerates ( $p$ $<0.001 ; \mathrm{df}=1.64 ; \mathrm{F}=40.72)$. Zooxanthellae comprised approximately 57 to $60 \%$ of symbiotic lacerate dry weight (Table 1) and there was no significant difference in percent lacerate dry weight attributable to zooxanthellae between newly generated lacerates and juvenile anemones (t-test of arcsine transformed data, $\mathrm{p}>0.90 ;$ df $=6 ; \mathrm{t}_{\mathrm{s}}=0.93$ ). Percent survival of newly generated lacerates to juvenile anemones showed no significant difference between symbiotic and aposymbiotic lacerates (t-test of arcsine transformed data, $p>0.50 ; \mathrm{df}=18 ; \mathrm{t}_{\mathrm{s}}=0.39$ ). In addition, there was no significant difference in development time between symbiotic and aposymbiotic lacerates (t-test, $\mathrm{p}>0.10 ; \mathrm{df}=28 ; \mathrm{t}_{\mathrm{s}}=1.61$ ).

\section{Lacerate production}

Total lacerate production by symbiotic and aposymbiotic anemones from varying feeding regimes is presented in Fig. 1. A 2-way ANOVA (Model I) of the ( $\mathrm{X}+$ $1 / 2)^{0.5}$ data $(\mathrm{X}=$ total number lacerates per anemone) tested for differences in lacerate production between symbionts and aposymbionts and between feeding regimes. There was no independent significant difference in lacerate production between symbiotic and aposymbiotic anemones ( $p>0.05 ; \mathrm{df}=1.54 ; \mathrm{F}=3.45$ ). However, there was a significant feeding regime effect ( $\mathrm{p}<0.001 ; \mathrm{df}=2.54 ; \mathrm{F}=22.45$ ) and a significant feeding regime-zooxanthellae interaction effect ( $p$ $<0.001$; df $=2,54 ; \mathrm{F}=11.80$ ).

\section{DISCUSSION}

Significance of zooxanthellae for lacerate development was examined by comparing several parameters of symbiotic and aposymbiotic lacerates. Symbiotic lacerates had a significantly greater dry weight than

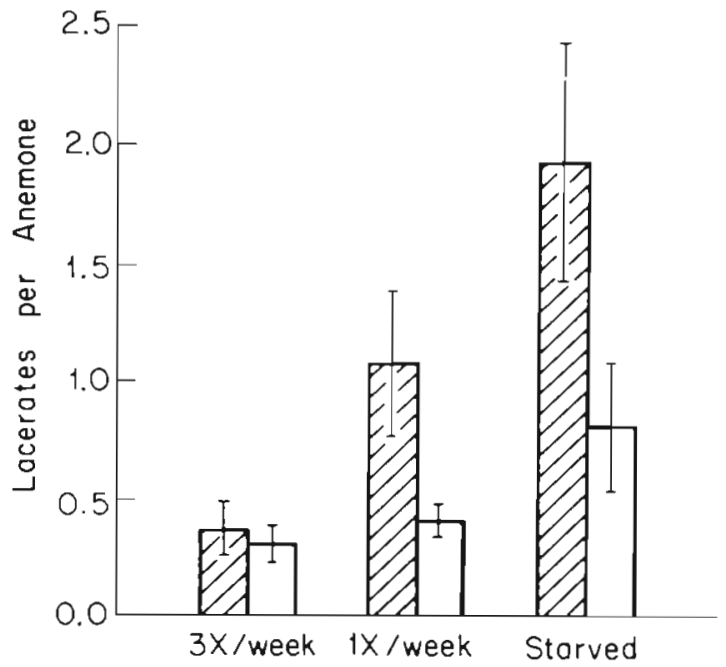

Fig. 1. Aiptasia pallida. Total lacerate production ( $\bar{X} \pm$ S. E.) of symbiotic (hatched bars) and aposymbiotic (open bars) anemones from varying feeding regimes after $30 \mathrm{~d}$. Analysis was performed on $(\bar{X}+1 / 2)^{0.5}$ data

aposymbiotic lacerates (Table 1). However, this difference can be attributed to the added weight of the zooxanthellae, which constituted 57 to $60 \%$ of symbiotic lacerate dry weight (Table 1). Mean symbiotic lacerate dry weight was $0.106 \mathrm{mg}$. However, animal dry weight per lacerate represented only about 40 to $45 \%$ of total lacerate dry weight, approximately 0.042 to $0.047 \mathrm{mg}$. This is comparable to the mean aposymbiotic lacerate dry weight of $0.036 \mathrm{mg}$ and suggests that animal biomass per lacerate was independent of zooxanthellae in the lacerating anemone. Contamination of the zooxanthellal pellet with animal tissue during separation may, as described previously, underestimate the animal biomass of symbiotic lacerates. Therefore, the possibility that symbiotic lacerates have more animal biomass than aposymbiotic lacerates cannot be ruled out. Improved separation procedures in the future may eliminate this difficulty.

Translocation of photosynthate from endosymbiotic algae to the host can enhance host growth and survival (Muscatine, 1961; Taylor, 1969; Sebens, 1977, 1980; 
Kinzie and Chee, 1979; Clayton, 1984). Presumably zooxanthellal effects on host growth and survival would have been greater in developing lacerates which are incapable of zooplankton feeding. However, in these experiments zooxanthellae had no significant effect on lacerate dry weight during development, lacerate development time or lacerate survival (Table 1). Animal biomass per lacerate did not change during development either, since total lacerate dry weight and percent dry weight attributable to zooxanthellae both remained constant during development (Table 1). These results suggest that, under these conditions, zooxanthellae did not affect lacerate development and support the previously suggested hypothesis that pedal lacerate development is principally a process of tissue reorganization and not synthesis of new tissue (Cary, 1911).

Results indicate that pedal laceration occurred randomly among individuals and among days. In all experiments the number of lacerates per individual and number of lacerates per day between feedings did not differ significantly from Poisson expectations (chisquare test of $s^{2} / \bar{X}$ for fit to Poisson distribution; Pielou, 1977). This suggests that all anemones were equally capable of undergoing pedal laceration on any given day. If pedal laceration were cued by a change in nutritional state related to the length of time since the last feeding I would expect non-random pedal laceration among days with most lacerates produced on those days furthest from the last scheduled feeding. Although laceration rate was affected by feeding regime, laceration apparently occurred at random among days between successive feedings. Starvation probably affected all individuals in a similar manner since all anemones were originally derived from a single individual. This suggests that starvation effects on pedal laceration were not a function of starvation duration but were related to long-term changes in anemone nutritional state associated with the varying feeding regimes. Zamer and Mangum (1979) showed a similar long-term effect of developmental temperature on oxygen uptake by Haliplanella luciae. In contrast, pedal laceration by Aiptasiogeton comatus does not occur randomly among days and usually occurs on those days furthest from the last feeding (Smith and Lenhoff, 1976).

Pedal laceration was inversely related to feeding frequency (Fig. 1). Starved symbiotic and aposymbiotic anemones produced significantly more lacerates than the corresponding individuals fed once per week or $3 X$ $\mathrm{w}^{-1}$ (Fig. 1). Similar effects of starvation on pedal laceration have been reported by Smith and Lenhoff (1976) for Aiptasiogeton comatus. Feeding also inhibits asexual reproduction (i.e. longitudinal fission) by Anthopleura elegantissima (Sebens, 1980).
Sebens (1979) developed and tested a model that predicts, among other things, the occurrence of asexual reproduction when prey item size and availability are known. In Anthopleura elegantissima energetic cost increases as a higher power of mass than does prey capture ability (Sebens, 1981), suggesting that larger individuals with reduced asexual reproduction will be found only in habitats with more available prey (Sebens, 1982a). The model further predicts that asexual reproduction producing smaller individuals can be energetically favored when food is limiting since total prey capture abilitiy increases while individual energetic cost decreases (Sebens, 1979, 1982b). Thus asexual reproduction may be a means for maximizing energetic surplus, i.e. the difference between energy intake and energy cost (Sebens, 1979), that can be used for both tissue growth and gonad development (Sebens, 1979, 1982a, b). In these experiments starvation increased lacerate production (Fig. 1) as predicted by Sebens' model.

Zooxanthellal effects on pedal laceration depended on feeding regime. For instance, symbiotic and aposymbiotic anemones did not differ significantly in lacerate production when fed either once per week or $3 \mathrm{X} \mathrm{wk} \mathrm{w}^{-1}$ (Fig. 1). However, zooxanthellae enhanced pedal laceration during starvation (Fig. 1). In contrast, Hunter (pers. comm.) has shown that symbiotic Aiptasia pulchella starved in the light for $8 \mathrm{wk}$ produced fewer lacerates than symbiotic anemones starved in the dark, suggesting that zooxanthellae inhibit pedal laceration during starvation.

Presumably zooxanthellal photosynthate translocated to the host would - at least partially - counteract the adverse effects of starvation on anemone nutritional state. Thus, if pedal laceration were cued only by nutritional state, we would expect aposymbiotic anemones to have greater rates of pedal laceration compared to symbiotic anemones from the same feeding regime since aposymbiotic individuals lack the nutritional advantage that symbiotic individuals derive from the zooxanthellae. However, in these experiments aposymbiotic anemones never produced more lacerates than symbiotic anemones.

In some instances asexual reproduction may be affected by factors other than energetic surplus. For instance, fission by Haliplanella luciae is enhanced by feeding (Minasian, 1976, 1979, 1982; Minasian and Mariscal, 1979) and conditions that maximize fission reduce clonal biomass (Minasian, 1982). Thus in those environments where fission rate is large, asexual reproduction by $H$. luciae may be advantageous for reasons other than energetic considerations (Minasian, 1982). For example, asexual reproduction may increase clone size for space competition with other organisms. Much evidence suggests that space is a major limiting 
resource in marine hard substrate environments (Loya, 1972; Connell, 1973; Porter, 1974; Jackson, $1977 \mathrm{a}$, b; Benayahu and Loya, 1981; and many others) and that, in some habitats, colonial animals are superior competitors compared to solitary animals (Jackson, 1977a). However, a more detailed study of the relation between feeding regime, pedal laceration and body size is necessary to provide a thorough test of current theories regarding the control of asexual reproduction.

Asexual reproduction is apparently a complex process which can be affected by culture conditions. In these experiments, the presence of zooxanthellae did not positively affect any aspect of lacerate development (Table 1) but did enhance lacerate production during starvation (Fig. 1). These zooxanthellae may represent one factor which can affect the rate of asexual reproduction by symbiotic cnidarians.

Acknowledgements. I thank M. A. Bisson, C. F. Herreid, J. F. Storr, K. P. Sebens, and especially H. R. Lasker, for valuable advice and discussion. The microbalance was made available by C. A. Privitera. Louise Scrocchi assisted in the laboratory and J. Clayton aided with the statistical analysis. Submitted in partial fulfillment for the degree of Doctor of Philosophy at the State University of New York at Buffalo.

\section{LITERATURE CITED}

Bak, R. P. M., Sybesma, J., Van Duyl, F. C. (1981). The ecology of the tropical compound ascidian Trididemnum solidum. Il. Abundance, growth, and survival. Mar. Ecol. Prog. Ser. 6: 43-52

Benayahu, Y., Loya, Y. (1981). Competition for space among coral-reef sessile organisms at Eilat, Red Sea. Bull. mar. Sci. 31: 514-522

Bossert, P., Slobodkin, L. B. (1983). The effect of fast, and regeneration in light vs. dark, on regulation in the hydraalgal symbiosis. Biol. Bull. mar, biol. Lab., Woods Hole 164: $396-405$

Brondsted, A., Brondsted, H. V. (1953). The effect of symbiotic zoochlorellae on the germination rate of gemmules of Spongilla lacustris. Vidensk. Meddr Danm. naturh. Foren. 115: 133-144

Cary, L. R. (1911). A study of pedal laceration in actinians. Biol. Bull. mar. biol. Lab., Woods Hole 20: 81-108

Chia, F. S. (1976). Sea anemone reproduction: patterns and adaptive radiation. In: Mackie, G. O. (ed.) Coelenterate ecology and behavior. Plenum Press, New York, p. 261-270

Clayton, W. S., Jr. (1984). Host-symbiont interactions in algalcnidarian symbioses. Ph. D. thesis, State University of New York at Buffalo, Buffalo, New York

Connell, J. H. (1973). Population ecology of reef-building corals. In: Jones, O. A., Endean, R. (ed.) Biology and geology of coral reefs. Academic Press, New York, p. 205-245

Francis, L. (1973a). Clone specific segregation in the sea anemone Anthopleura elegantissima. Biol. Bull. mar, biol. Lab., Woods Hole 144: 64-72

Francis, L. (1973b). Intraspecific aggression and its effect on the distribution of Anthopleura elegantissima and some related anemones. Biol. Bull. mar, biol. Lab., Woods Hole 144: 73-92

Francis, L. (1976). Social organization within clones of the sea anemone Anthopleura elegantissima. Biol. Bull. mar. biol. Lab., Woods Hole 150: 361-376

Francis, L. (1979). Contrast between solitary and colonial lifestyles in the sed anemone Anthopleura elegantissima. Am. Zool. 19: 669-681

Hoffmann, D. K., Kremer, B. P. (1981). Carbon metabolism and strobilation in Cassiopea andromeda, significance of endosymbiotic dinoflagellates. Mar. Biol. 65: 25-33

Hofmann, R. J (1976). Genetics and asexual reproduction of the sea anemone Metridium senile. Biol. Bull. mar. biol. Lab., Woods Hole 151: 478-488

Hughes, T. P., Jackson, J. B. C. (1980). Do corals lie about their age? Some demographic consequences of partial mortality, fussion and fission. Science, N. Y. 209: 713-715

Jackson, J. B. C. (1977a). Competition on marine hard substrata. The adaptive significance of solitary and colonial strategies. Am. Nat. 111: 743-763

Jackson, J. B. C. (1977b). Habitat area, colonization, and development of epibenthic community structure. In: Keegan, B. F., Ceidigh, P. O., Boaden, P. J. S. (ed.) Biology of benthic organisms. Pergamon Press, London, p. 349-358

Johnson, L. L., Shick, J. M. (1977). Effects of fluctuating temperature and immersion on asexual reproduction in the intertidal sea anemone Haliplanella luciae in laboratory culture. J. exp. mar. Biol. Ecol. 28: 141-149

Kinzie, R. A., Chee, G. S. (1979). The effect of different zooxanthellae on the growth of experimentally reinfected hosts. Biol. Bull. mar, biol. Lab., Woods Hole 156: 315-327

Loya, Y (1972). Community structure and species diversity of hermatypic corals at Eilat. Mar. Biol. 13: 100-123

Ludwig, L. D. (1969). Die Zooxanthellen bei Cassiopea andromeda und ihre Bedeutung für die Strobilation. Zool. Jb. (Anat.) 86: 238-277

Minasian, L. L., Jr. (1976). Characteristics of asexual reproduction in the sea anemone, Haliplanella luciae, reared in the laboratory. In: Mackie, G. O. (ed.) Coelenterate ecology and behavior. Plenum Press, New York, p. 289-298

Minasian, L. L., Jr. (1979). The effect of exogenous factors on morphology and asexual reproduction in laboratory cultures of the intertidal sea anemone, Haliplanella luciae from Delaware. J. exp. mar. Biol. Ecol. 40: 235-246

Minasian, L. L., Jr. (1982). The relationship of size and biomass to fission rate in a clone of the sea anemone Haliplanella luciae. J. exp. mar. Biol. Ecol. 58: 151-162

Minasian, L. L., Jr., Mariscal. R. N. (1979). Characteristics and regulation of fission activitiy in clonal cultures of the cosmopolitan sea anemone Haliplanella luciae. Biol. Bull. mar. biol. Lab., Woods Hole 157: 478-493

Muscatine, L. (1961). Symbiosis in marine and freshwater coelenterates. In: Lenhoff, W. M., Loomis, W. F. (ed.) The biology of Hydra. University of Miami Press, Miami, p. 255-268

Pielou, E. C. (1977). Mathematical ecology, John Wiley and Sons, New York

Porter, J. W. (1974). Community structure of coral reefs on opposite sides of the isthmus of Panama. Science, N. Y. 186: $543-545$

Rahat, M., Reich, V. (1983). A comparative study of tentacle regeneration and number in symbiotic and aposymbiotic Hydra viridis: effect of zoochlorellae. J. exp. Zool. 227 : $63-68$

Sebens, K. P. (1977). Autotrophic and heterotrophic nutrition of coral reef zoanthids. Proc. Third. Int. Coral Reef Symp. 1: $398-404$ 
Sebens, K. P. (1979). The energetics of asexual reproduction and colony formation in benthic marine invertebrates. Am. Zool. 19: 683-697

Sebens, K. P. (1980). The regulation of asexual reproduction and indeterminate body size in the sea anemone Anthopleura elegantissima. Biol. Bull. mar. biol. Lab., Woods Hole 158: $370-382$

Sebens, K. P. (1981). The allometry of feeding, energetics, and body size in three sea anemone species. Biol. Bull. mar. biol. Lab., Woods Hole 161: 152-171

Sebens, K. P. (1982a). The limits to indeterminate growth: an optimal size model applied to passive suspension feeders. Ecology 63: 209-222

Sebens, K. P. (1982b). Asexual reproduction in Anthopleura elegantissima: seasonality and spatial extent of clones. Ecology 63: 434-444

Shick, J. M., Hoffman, R. J. (1980). Effects of the trophic and physical environments on asexual reproduction and body size in the sea anemone Metridium senile. In: Tardent, P., Tardent, R. (ed.) Developmental and cellular biology of coelenterates. Elsevier Biomedical Press, Amsterdam, p. $211-216$

Shick, J. M., Lamb, A. N. (1977). Asexual reproduction and genetic population structure in the colonizing sea anemone Haliplanella luciae. Biol. Bull. mar. biol. Lab., Woods Hole 153: 604-617

Shick, J. M., Hoffmann, R. J., Lamb, A. N. (1979). Asexual reproduction population structure, and genotype-environment interactions in sea anemones. Am. Zool. 19: 699-713
Smith, N., III, Lenhoff, H. M. (1976). Regulation of pedal laceration in a sea anemone. In: Mackie, G. O. (ed.) Coelenterate ecology and behavior. Plenum Press, New York, p. 117-125

Sokal, R., Rohlf, F. (1969). Biometry, W. H. Freeman and Co., San Francisco

Stephenson, T. A. (1929). On methods of reproduction as specific characters. J. mar. biol. Ass. U. K. 16: 131-172

Sugiura, Y. (1964). On the life history of rhizostome medusae. II. Indispensability of zooxanthellae for strobilation in Mastigias papua. Embryologia 8: 223-233

Taylor, D. L. (1969). On the regulation and maintenance of algal numbers in zooxanthellae-coelenterate symbiosis, with a note on the relationship in Anemonia sulcata. J. mar. biol. Ass. U. K. 49: 1057-1065

Trench, R. K. (1980). Integrative mechanisms in mutualistic symbioses. In: Cook, C. B., Pappas, P. W. (ed.) Cellular interactions in symbiosis and parasitism. Ohio State University Press, Colombus, p. 275-297

Vandermeulen, J. H., Davis, N. D., Muscatine, L. (1972). The effect of inhibitors of photosynthesis on zooxanthellae in corals and other marine invertebrates. Mar. Biol. 16: 183-191

Zamer, W. E., Mangum, C. P. (1979). Irreversible nongenetic temperature adaptation of oxygen uptake in clones of the sea anemone Haliplanella luciae. Biol. Bull. mar. biol. Lab., Woods Hole 157: 536-547

This paper was presented by Dr. R. S. Scheltema; it was accepted for printing on September 14, 1984 